\title{
Trends of Automation of Integrated Microfluidics
}

Raymond HW Lam *

Department of Mechanical and Biomedical Engineering, City University of Hong Kong, Hong Kong

\section{Introduction}

In the past decades, research efforts in microfluidics - an enabling technology to perform automated operations on fluid using submicroliter volumes - have rapidly expanded in terms of both theoretical studies and applications [1]. Microfluidic devices can handle small volume of fluids, extending down to attoliter-scale volumes in forms of droplets or liquid sections in confined micro-channels, which can be applied a large variety of biological solutions (e.g. enzymes, nucleic acids, antibodies or cells). Such devices offer excellent portability, in form of bench-top devices, and controllability, with manipulations of molecules or cells in micro-channels/chambers with dimensions in the order of $\sim 10-100 \mu \mathrm{m}$. Microfluidic devices have also been used to precisely control the in vitro biofilm environment. Development of microfluidic devices has become a cross-disciplinary effort, often involving different aspects of science and engineering, including optics, biology, chemistry, mechanics and material science [2]. Some of the major advantages of the device miniaturization are the reduction in biological and chemical wastes production, precise fluid handling, faster analysis and molecular-based detection, and the capability to carry out parallel or high-throughput operations [3]. In particular, the length scale of microfluidic systems increases the speed of common experimental techniques, such as protein and DNA electrophoresis, by orders of magnitude. As a tool for cellular culture, microfluidics is a tool that enables researchers to spatiotemporally regulate the environment around cell populations at different scales, ranging from single cells to thousands/millions of cells.

The implementation of traditional laboratory work with microfluidic chips is often called "micro total analysis systems ( $\mu \mathrm{TAS}$ )" or "lab-on-a-chip (LOC)", and the biocompatibility and biological/ chemical stability of the device material is a serious issue. While silicon-based micro devices manufactured with methods developed in the semiconductor industry were some of the earliest examples of microfluidics-based research, there has been a shift over the last decade towards polymer-based devices, using materials such as Teflon, thermoset polyesters, silicon elastomer photoresist, SU-8 photoresist, poly-dimethylsiloxane (PDMS) and poly-methyl methacrylate [4-7]. Silicone rubber-based chemostats [8], bioreactors [9-12], and other microfluidic platforms $[13,14]$ containing multiple cell chambers have been successfully applied in the cell culture applications in recent years. These microfluidic devices, consisting of optically-transparent PDMS, were fabricated using a casting process from silicon wafer molds containing photoresists with positive-relief channel patterns. The fabrication is based on both standard lithographic techniques [15] for a single layer of channel networks, and multilayer soft lithography [16], which uses stacked two-dimensional networks of microchannels to add functional valves and pumps on chip, for example.

On the other hand, examples of applied microfluidic research in microbiology include the quantification of bacteria in environmental samples [17], toxin detection in food samples [18], saliva-based detection of infectious diseases [19], and characterization of bacterial transport parameters [20]. A device was developed to study the biofilm morphology forming under shear by imposing different flow velocities [21]. An integrated microfluidic chip has also been used for monitoring cell culture, including the monitoring of culture density over time and the probing cellular functions at a single-cell level [22]. While there have been many good examples of microfluidic tools introduced for cell typing, primarily using modified immunoassay protocols, organism identification using nucleic-acid based probes, while potentially faster and easier to develop for a specific strain, is still challenging [23]. Nucleic-acid based assays, using techniques such as fluorescence in situ hybridization (FISH), have broad applications that extend beyond typing, including gene expression monitoring in individual cells [24], and the chromosomal analysis for mammalian cells [25]. The optimization of FISH assays for biofilm analysis is particularly interesting, as probes targeting the highly-conserved $16 \mathrm{~S}$ ribosomal ribonucleic acid (rRNA), for example, can be used to identify species variants within a multiple-species co-culture.

While microfluidics has enabled tremendous possible of detailed biological and biochemical analyses, setting up a matrix of experimental conditions to mimic the microenvironments for formations of multiple-species biofilms and even complex tissues present in human body remains a laborious process. Together, we look forward to the development of a highly integrated microfluidic device which can support the spatiotemporal control of multiple parameters, such as nutrients concentration, oxygen level and microorganism composition. The corresponding throughput should obtain a significant improvement in the chamber density versus existing state-of-the-art microfluidic systems, such that the time for characterization of biofilm can be greatly shortened. With the further advancements of control and automation of integrated microfluidics, our understanding of cell, biochemical and molecular sciences can then be greatly deepened.

\section{References}

1. Gomez R, Bashir R, Sarikaya A, Ladisch MR, Sturgis J, et al. (2001) Microfluidic Biochip for Impedance Spectroscopy of Biological Species. Biomedical Microdevices 3: 201-209.

2. Barber R, Emerson D (2008) Optimal design of microfluidic networks using biologically inspired principles. Microfluidics and Nanofluidics 4: 179-191.

3. Ertl P, Emrich CA, Singhal P, Mathies RA (2004) Capillary electrophoresis chips with a sheath-flow supported electrochemical detection system. Anal Chem 76: 3749-3755.

4. Ionescu-Zanetti C, Shaw RM, Seo J, Jan YN, Jan LY, et al. (2005) Mammalian electrophysiology on a microfluidic platform. Proc Natl Acad Sci U S A 102 : 9112-9117.

5. Becker H, Gartner C (2008) Polymer microfabrication technologies for microfluidic systems. Anal Bioanal Chem 390: 89-111.

*Corresponding author: Raymond HW Lam, Department of Mechanical and Biomedical Engineering, City University of Hong Kong, Hong Kong, Tel: 852 3442 8577, E-mail: rhwlam@cityu.edu.hk

Received March 10, 2014; Accepted March 10, 2014; Published March 12, 2014

Citation: Lam RHW (2014) Trends of Automation of Integrated Microfluidics. Adv Robot Autom 3: e119. doi: 10.4172/2168-9695.1000e119

Copyright: @ 2014 Lam RHW. This is an open-access article distributed under the terms of the Creative Commons Attribution License, which permits unrestricted use, distribution, and reproduction in any medium, provided the original author and source are credited. 
6. Mukhopadhyay R (2007) When PDMS isn't the best. What are its weaknesses, and which other polymers can researchers add to their toolboxes? Anal Chem 79: 3248-3253

7. Duffy DC, McDonald JC, Schueller OJ, Whitesides GM (1998) Rapid Prototyping of Microfluidic Systems in Poly(dimethylsiloxane). Anal Chem 70: 4974-4984.

8. Sia SK, Whitesides GM (2003) Microfluidic devices fabricated in poly(dimethylsiloxane) for biological studies. Electrophoresis 24: 3563-3576.

9. Balagadde FK, You L, Hansen CL, Arnold FH, Quake SR (2005) Longterm monitoring of bacteria undergoing programmed population control in a microchemostat. Science 309: 137-140.

10. Alex G, Caroline L, HoJung C, Kyle CJ, Yann SD, et al. (2005) A microfluidic chemostat for experiments with bacterial and yeast cells. Nat Methods 2: 685689

11. Zhang Z, Boccazzi P, Choi HG, Perozziello G, Sinskey AJ, et al. (2006) Microchemostat-microbial continuous culture in a polymer-based, instrumented microbioreactor. Lab Chip 6: 906-913.

12. Lee PJ, Hung PJ, Rao VM, Lee LP (2006) Nanoliter scale microbioreactor array for quantitative cell biology. Biotechnol Bioeng 94: 5-14

13. Lee HL, Boccazzi P, Ram RJ, Sinskey AJ (2006) Microbioreactor arrays with integrated mixers and fluid injectors for high-throughput experimentation with $\mathrm{pH}$ and dissolved oxygen control. Lab Chip 6: 1229-1235.

14. Szita N, Boccazzi P, Zhang Z, Boyle P, Sinskey AJ, et al. (2005) Development of a multiplexed microbioreactor system for high-throughput bioprocessing. Lab Chip 5: 819-826.

15. Xia Y, Whitesides GM (1998) Soft Lithography. Annual Review of Materials Science 28: 153-184
16. Unger MA, Chou HP, Thorsen T, Scherer A, Quake SR (2000) Monolithic microfabricated valves and pumps by multilayer soft lithography. Science 288 : 113-116

17. Sakamoto C, Yamaguchi N, Nasu M (2005) Rapid and simple quantification of bacterial cells by using a microfluidic device. Appl Environ Microbiol 71: 11171121.

18. Palchetti I, Mascini M (2008) Electroanalytical biosensors and their potential for food pathogen and toxin detection. Anal Bioanal Chem 391: 455-471.

19. Starke EM, Smoot JC, Wu JH, Liu WT, Chandler D, et al. (2007) Saliva-based diagnostics using 16S rRNA microarrays and microfluidics. Ann N Y Acad Sci 1098: 345-361.

20. Ahmed T, Stocker R. (2008) Experimental verification of the behaviora foundation of bacterial transport parameters using microfluidics. Biophys $\mathrm{J} 95$ 4481-4493.

21. Lee JH, Kaplan JB, Lee WY (2008) Microfluidic devices for studying growth and detachment of Staphylococcus epidermidis biofilms. Biomed Microdevices 10: $489-498$

22. Bao N, Wang J, Lu C (2008) Recent advances in electric analysis of cells in microfluidic systems. Anal Bioanal Chem 391: 933-942.

23. Saleh-Lakha S, Trevors JT (2010) Perspective: microfluidic applications in microbiology. J Microbiol Methods 82: 108-111.

24. Marcus JS, Anderson WF, Quake SR (2006) Microfluidic single-cell mRNA isolation and analysis. Anal Chem 78: 3084-3089.

25. Sieben VJ, Debes-Marun CS, Pilarski LM, Backhouse CJ (2008) An integrated microfluidic chip for chromosome enumeration using fluorescence in situ hybridization. Lab Chip 8: 2151-2156. 